الحالة التذذوية للمرأة الريفية الحامل وعلاقتها ببعضر المتغيرات المؤثرة عليها في بعض قرى محافظة الإسكندرية

آمال السيد محمود العسال

معهد بحوث الإرشاد الزراعي و التنمية الريفية - مركز البحوث الزراعية - جيزة - مصر

المستخلص

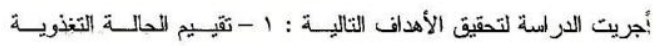

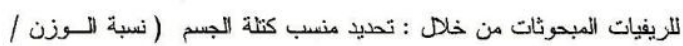

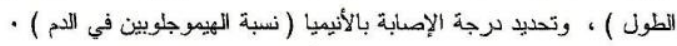

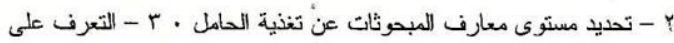

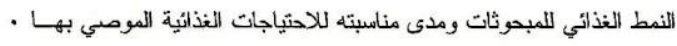

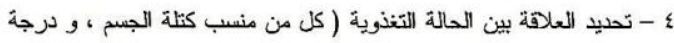

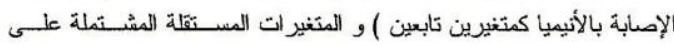

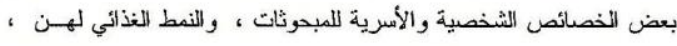
ومستوى معارفهن عن تغذية الحامل .

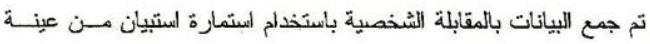

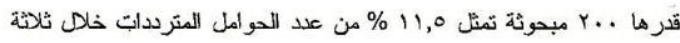

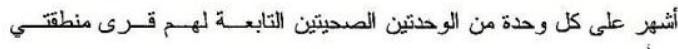

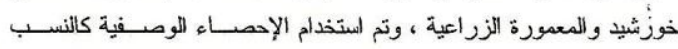

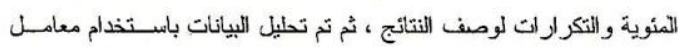

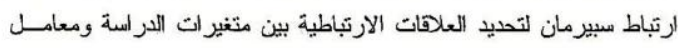

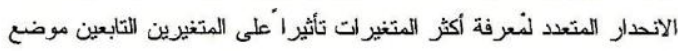

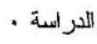

أسفرت أهم نتائج البحث عما يلي :

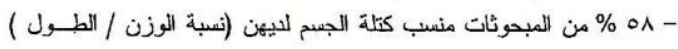

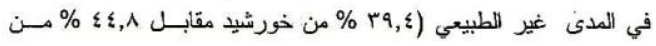

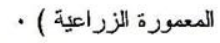

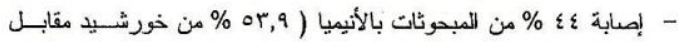

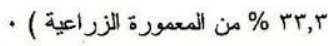

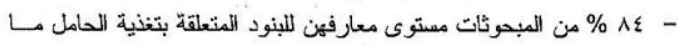

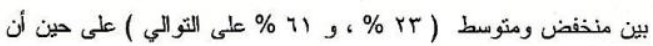

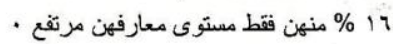

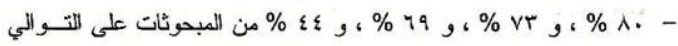

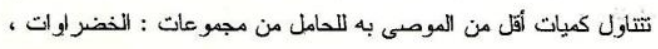




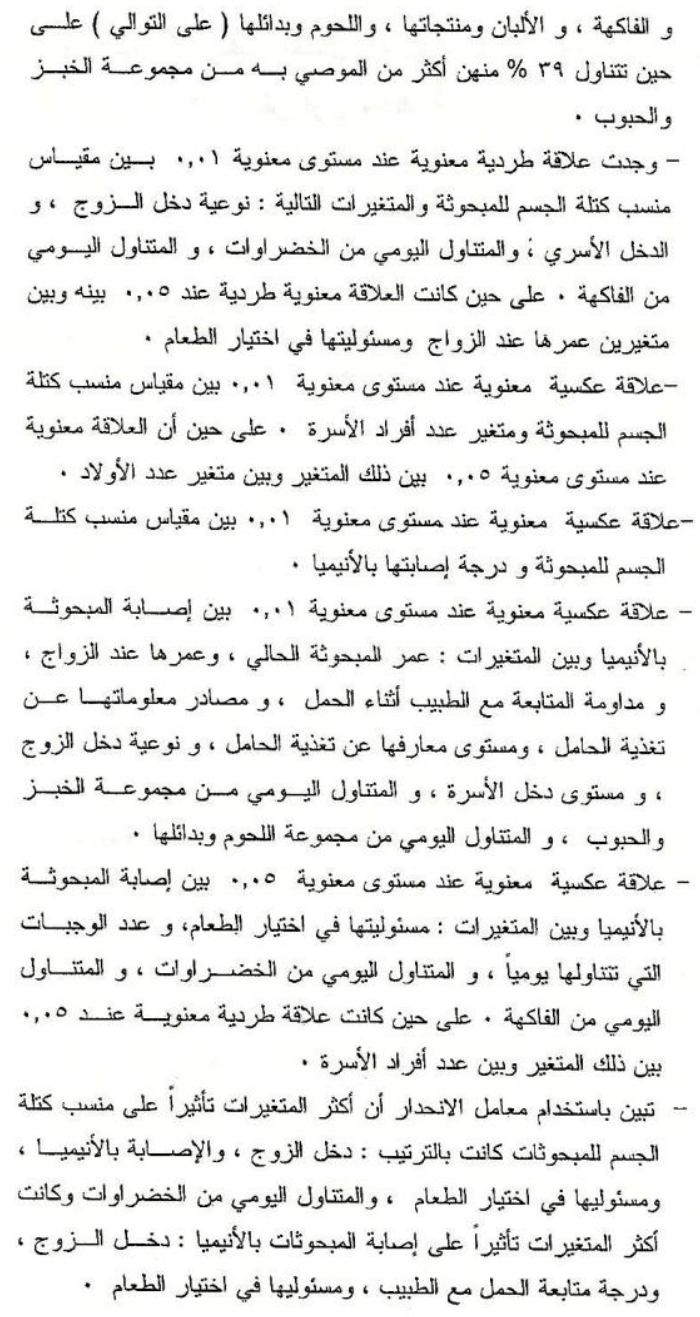




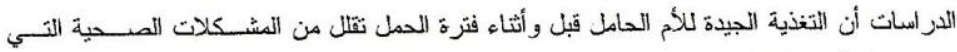

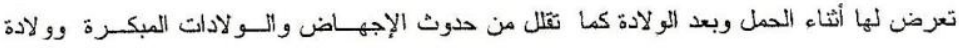

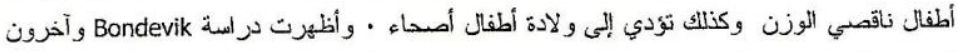

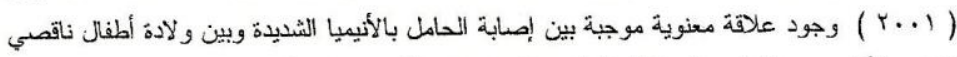

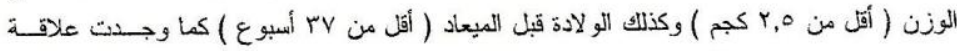

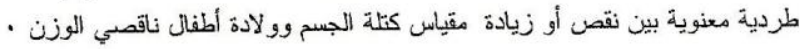

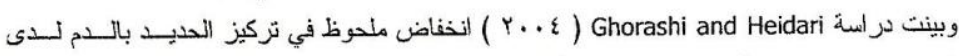

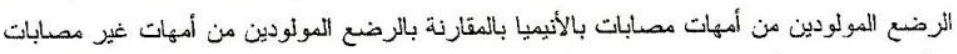

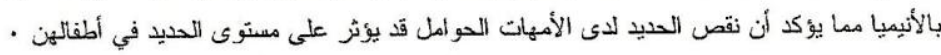

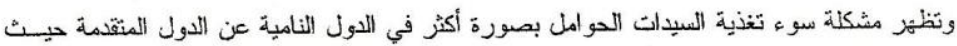

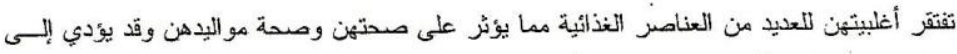

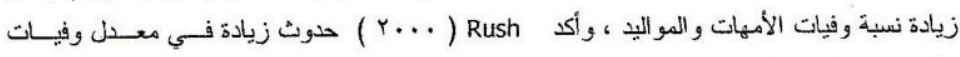

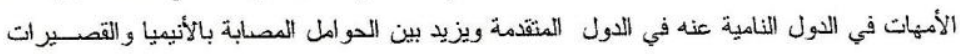
القامة . الأحن

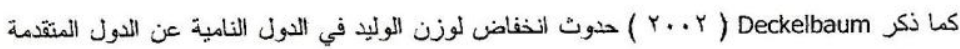

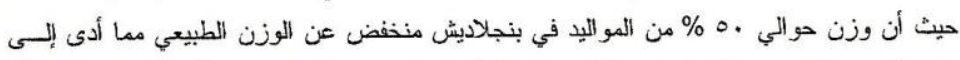

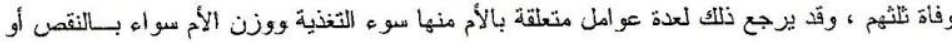

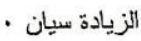

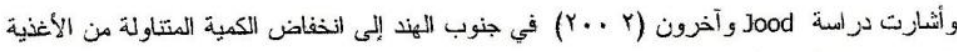

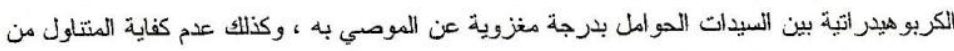

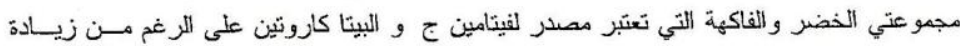

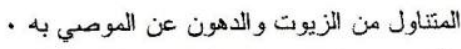

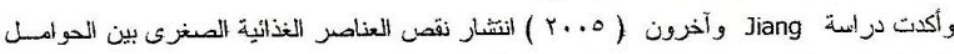

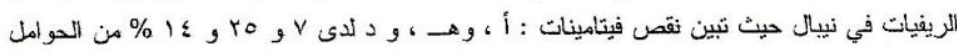

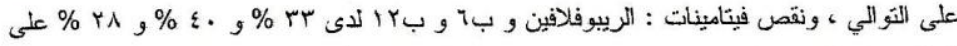

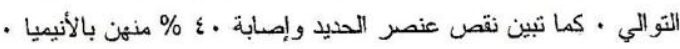

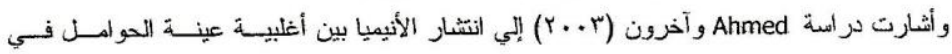
بنجلاديش بن ونتأثر الحالة التغذوية للأم الحامل ببعض العوامل الاجنماعية والاقتصادية والصحية وأهمها العمر

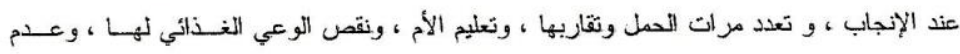

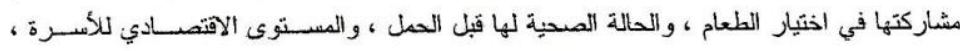

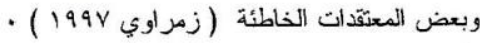

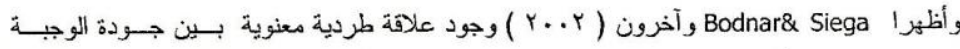

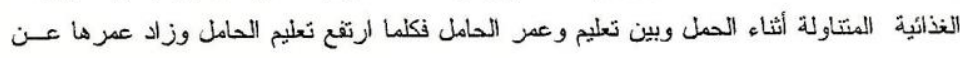


•ب سنة كلما تتاولت وجبة أكثر جودة وزادت كمية الحديد المثتاول في الوجبــة كمــا زادت حصسـة

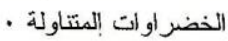

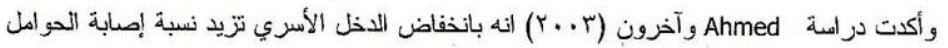

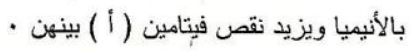

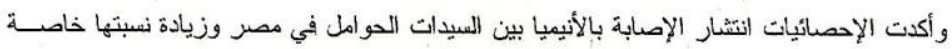

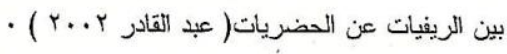

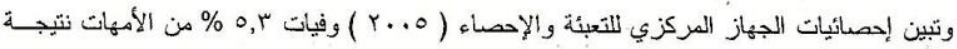

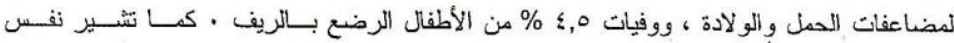

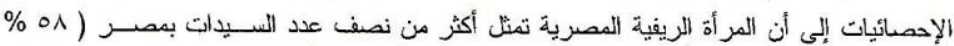

- من

$$
\text { أهداف البحث }
$$

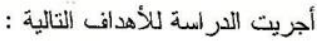

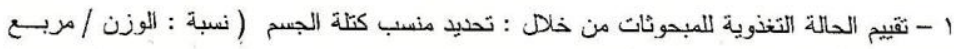

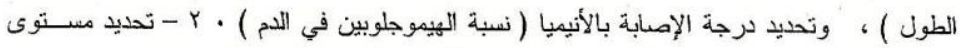

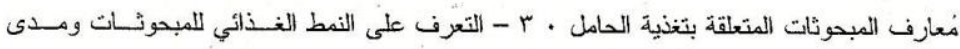

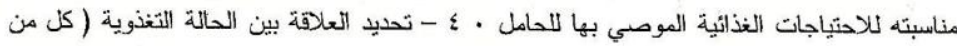

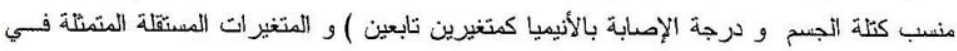

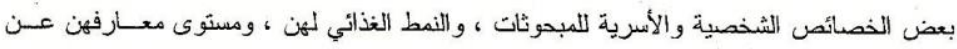
· تغذية الحامل

\section{فروض البحث}

تم صياغة الفروض البحثية لتحقق الهدف الرابع للار اسة كما يلي :

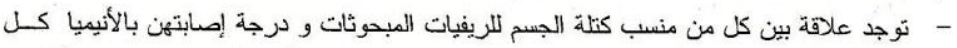

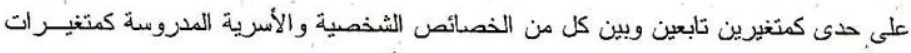
مستقلة

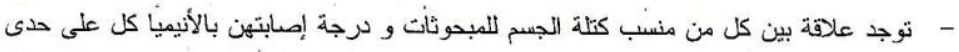

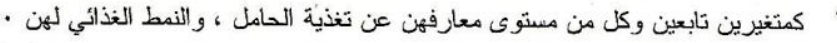

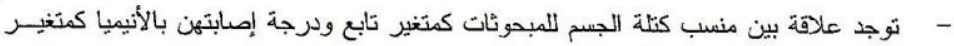

\section{الطريقة البحثية}

- مستقل

أولاً : منطقة البحث ووعينته:

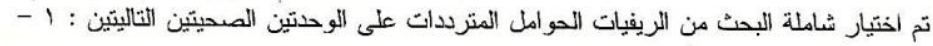

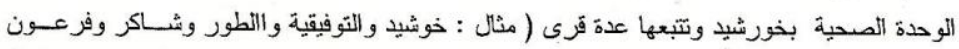

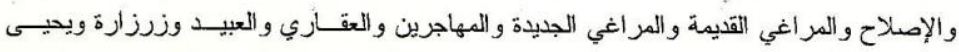




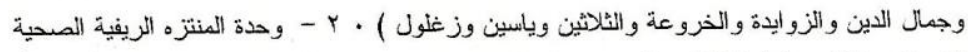

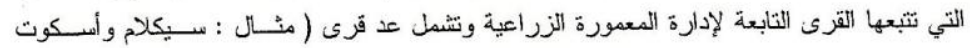

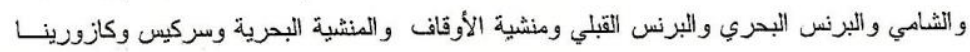

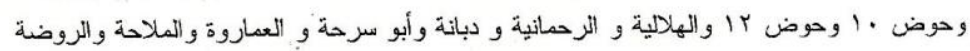

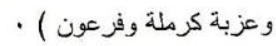

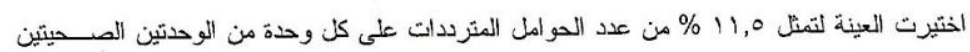

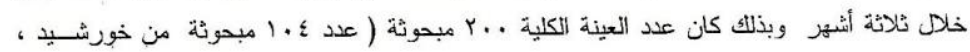

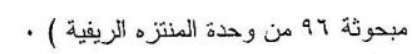

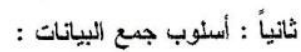

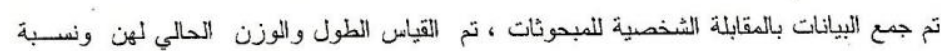

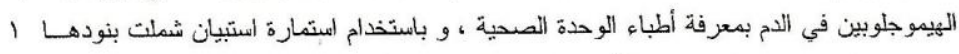

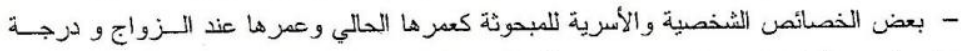

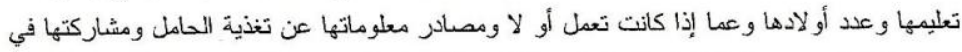

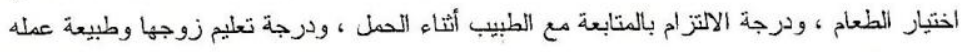

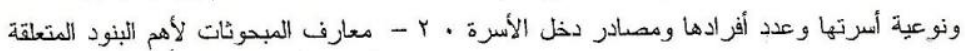

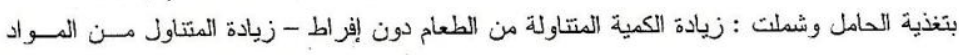

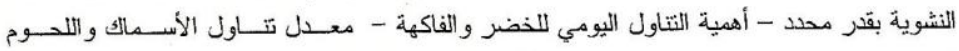

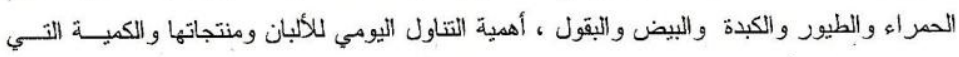

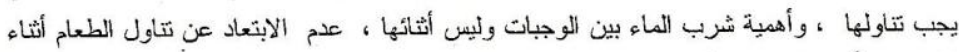

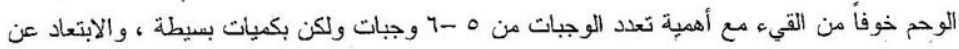

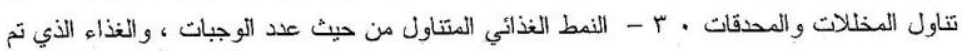

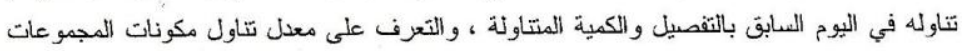

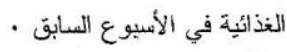

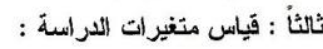

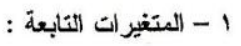

تم تقييم. الحالة التخذوية المبحوثة بطريقتين (استخدم كل منهما كمنغير تابع ) هما : أ - قيـاس

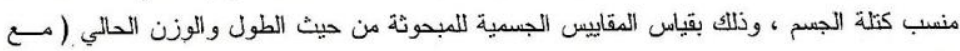

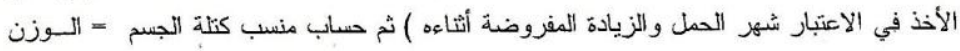

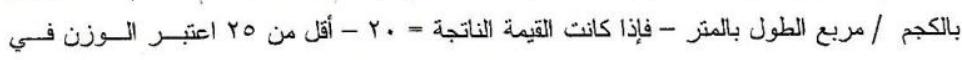

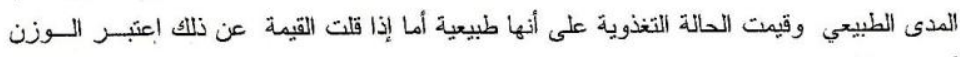
أقل من الطبيعي و إذا ذاد اعتبر الوزن أكثر من الطبيعي ، وفي كلاهما نعتبر الحالة التغذوية سيئة ، وتم التحويل الكمي بأن تأخذ المقاييس الطبيعية درجة واحدة وغيبر الطبيعية (سواء بالنقص أو الزيادة)

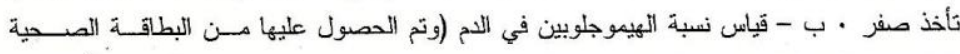

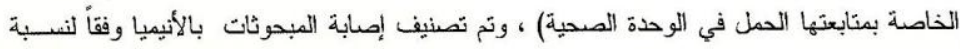




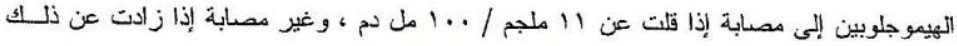

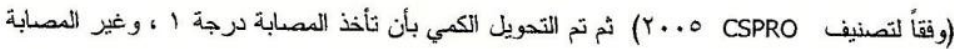

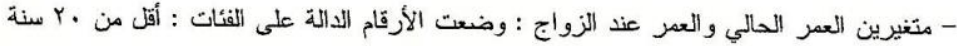

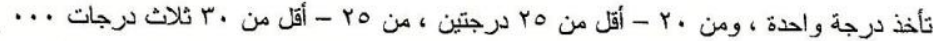

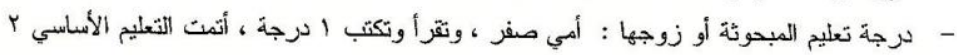

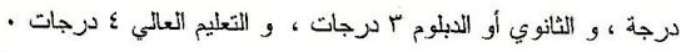

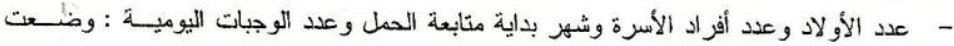

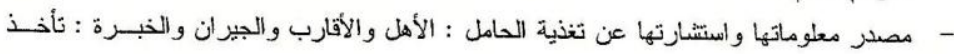

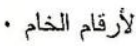

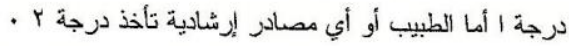

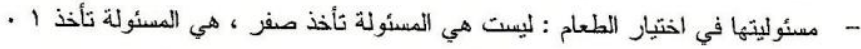

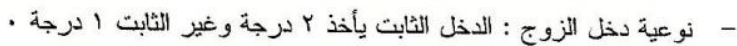

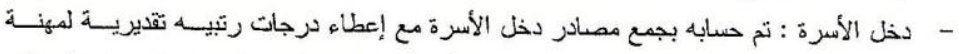

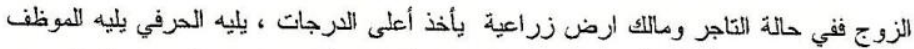

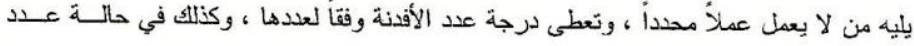
رؤس الماشية من لآل

- - المستوى المعرفي للمبحوثة بالتغذية المليمة الحامل : تم قياسه من خلال ستة عشر عبارة (17)

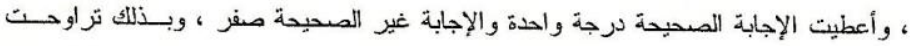

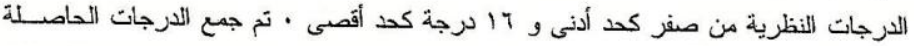

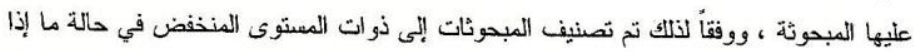

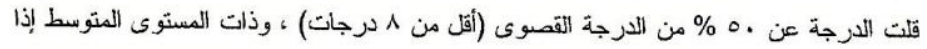

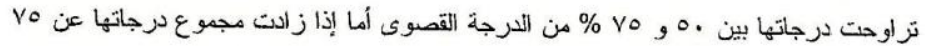

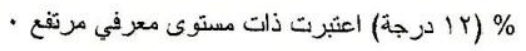

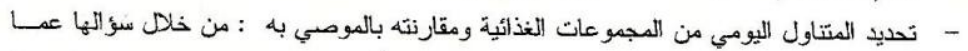

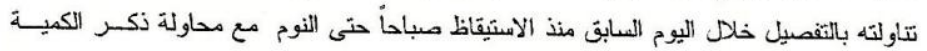

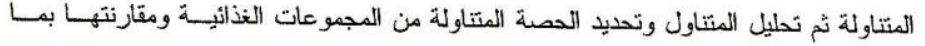

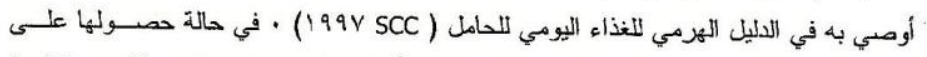

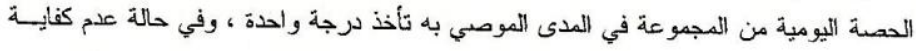

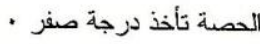
رابعاً : التحليل الإحصائي للبياتات :

تم تحليل البيانات إحصائياً باستخدام البرنامج الإحصائي الحزمة الإحصائية للعلوم الاجنماعية

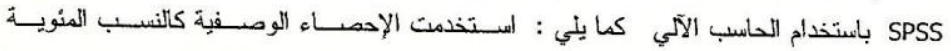




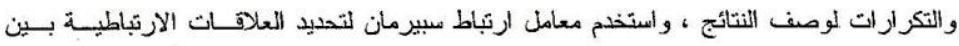

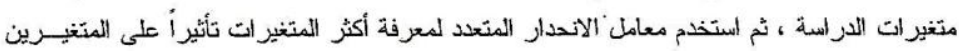

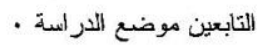

\section{النتائج و المناقشة}

أولاً: تقييم الحالة التغذوية للمبحوثات :

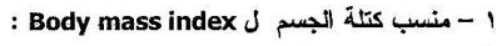

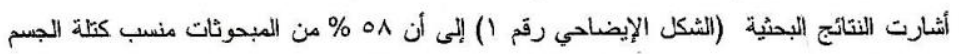

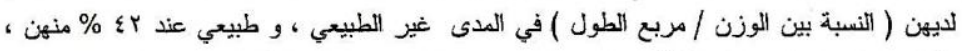

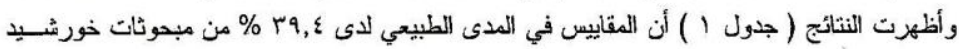

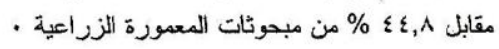
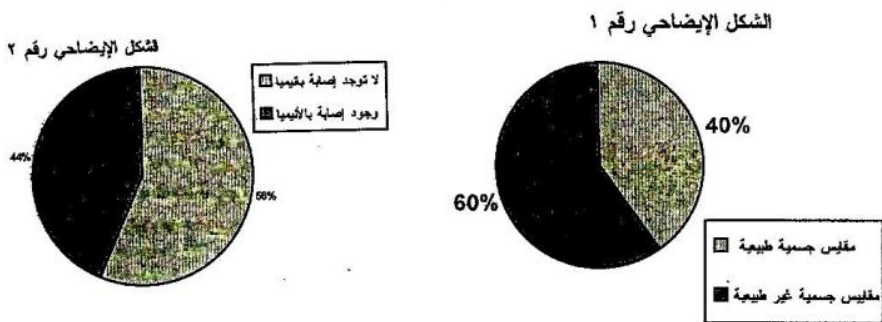

إلحالة التغذوية للمبحوثات

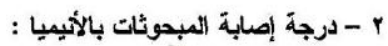

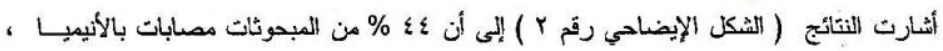

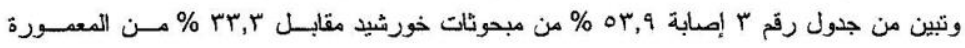

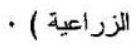

جدول ا ـ توزيع المبحوثات وفقاً لمنسب كثلة الجسم

\begin{tabular}{|c|c|c|c|c|c|c|}
\hline \multicolumn{2}{|c|}{ إجمالي العينة } & \multicolumn{2}{|c|}{ مبحوثــات المعمــورة } & \multicolumn{2}{|c|}{ مبحوثات خورشيد } & \multirow[t]{2}{*}{ منسب كتلة الجسم } \\
\hline$\%$ & العدد & $\%$ & العدد & $\%$ & العدد & \\
\hline$\varepsilon r$ & $\Lambda \varepsilon$ & $\varepsilon \varepsilon, \Lambda$ & \&r & rq, ह & §1 & في المدى الطبيعي \\
\hline rq & VA & ro,. & $r \varepsilon$ & $01,$. & r & أقل من المدى الطبيعي \\
\hline 19 & rA & $r \cdot, r$ & rq & 9,7 & 1. & أكثر من المدى الطبيعي \\
\hline $1 \cdots$ & r.. & $1 \cdots$ & १५ & $1 \cdots$ & $1 . \varepsilon$ & المجموع \\
\hline
\end{tabular}


جدول r ـ ـ توزيع المبحوثات وفقاً لمستوى الهيموجلوبين في الدم

\begin{tabular}{|c|c|c|c|c|c|c|}
\hline \multicolumn{2}{|c|}{ إجمالي العينة } & \multicolumn{2}{|c|}{ مبحوثات المعمورة الززر اعية } & \multicolumn{2}{|c|}{ مبحوثات خورشيد } & \multirow{2}{*}{ مستوى الهيموجلوبين في الدم } \\
\hline$\%$ & 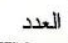 & $\%$ & 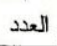 & $\%$ & 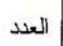 & \\
\hline 0.7 & $11 \mathrm{r}$ & $74, \mathrm{~V}$ & $7 \varepsilon$ & $\{1,1$ & $\varepsilon \wedge$ & 1 (أكثر ( لا يوجد أنيميا ) \\
\hline rr & $7 \varepsilon$ & $r \wedge, 1$ & YV & $r 0, T$ & rv & . - - 9, (1 (أنيميا بسيطة ) \\
\hline ir & $r \varepsilon$ & $0, r$ & $\circ$ & $11, r$ & 19 & 9, - - V ( أنيميا متوسطة ) \\
\hline $1 \ldots$ & r.. & $1 \ldots$ & 97 & $1 \ldots$ & $1 . \varepsilon$ & المجموع \\
\hline
\end{tabular}

ثاتياً : مستوى معارف المبحوثات للبنود المتعقةة بالتغذية السليمة للحامل :

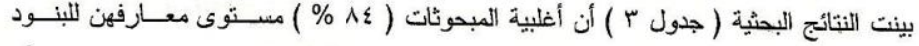

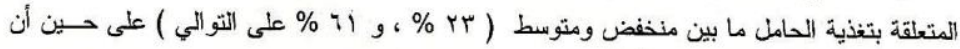

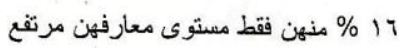

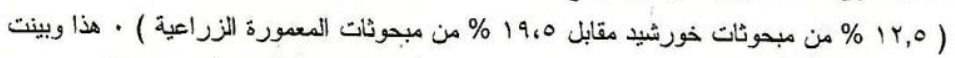

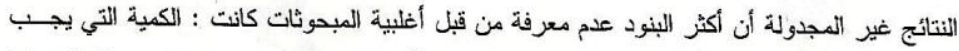

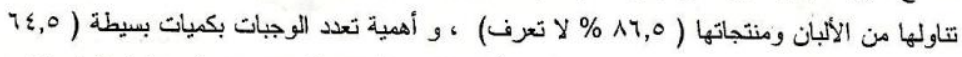

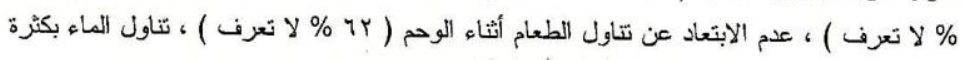

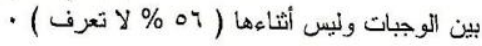

جدول س. توزيع المبحوثات وفقاً لمستوى معارفهن للبنود المنتعلقة بتغذية الحامل

\begin{tabular}{|c|c|c|c|c|c|c|}
\hline \multicolumn{2}{|c|}{ إجمالي العينة } & \multicolumn{2}{|c|}{ مبحوثات المعمورة } & \multicolumn{2}{|c|}{ مبحوثات خورثيد } & \multirow[t]{2}{*}{ المستوى المعرفي } \\
\hline$\%$ & العدد & $\%$ & العدد & $\%$ & 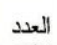 & \\
\hline Tr & $\varepsilon 7$ & $r v, 1$ & ry & $r \cdot, r$ & rI & منخفض \\
\hline 71 & Irr & or, 1 & 01 & $7 V, r$ & $\mathrm{ve}$ & متوسط \\
\hline 14 & r & 19,1 & 19 & $1 r, 0$ & ir & مرنقع \\
\hline $1 \cdots$ & r... & $1 \ldots$ & 94 & $1 \ldots$ & $1 \cdot \varepsilon$ & المجموع \\
\hline
\end{tabular}


ثابثاً : النمط الغذائي للمبحوثات :

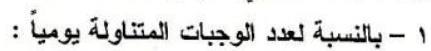

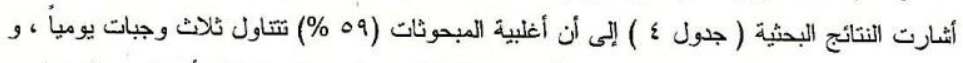

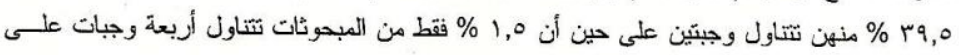

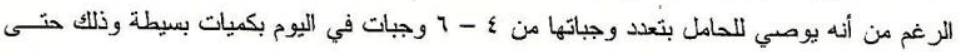
تتجنب القيء أو تخفف من حدته خاصة أثناء الوحم و تحصل على على احتياجاتها الغذائية ( الدنثــاري

$$
\text { ( } 199 .
$$

جدول ؛ ـ توزيع المبحوثات وفقاً لعدد الوجبات المتتاولة يومياً

\begin{tabular}{|c|c|c|c|c|c|c|}
\hline \multicolumn{2}{|c|}{ إجمالي العينة } & \multicolumn{2}{|c|}{ مبحوثات المعدورة } & \multicolumn{2}{|c|}{ مبحوثات خورشيد } & \multirow[t]{2}{*}{ عدد الوجبات } \\
\hline$\%$ & العدد & $\%$ & العدد العد & $\%$ & العدد & \\
\hline$r 9,0$ & vq & $r q, 7$ & r & $r \wedge, 0$ & $\varepsilon$. & وجبيَين \\
\hline$\circ 9$, & 111 & $T \cdot, \varepsilon$ & $0 \wedge$ & $0 \wedge, V$ & 11 & ثلاث وجبات \\
\hline 1,0 & r & - & - & $r, \Lambda$ & r & أكثر من ثلات وجبات \\
\hline $1 \ldots$ & r.. & $1 \ldots$ & 97 & $1 \ldots$ & $1 . \varepsilon$ & المجموع \\
\hline
\end{tabular}

r - العصة اليومية المتناولة من المجموعات الغذائية :

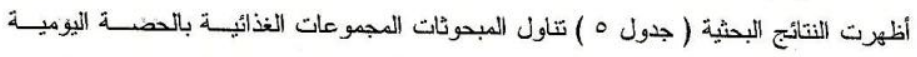

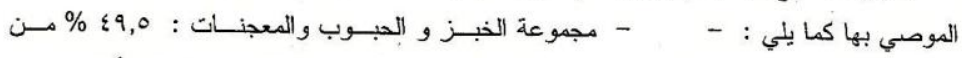

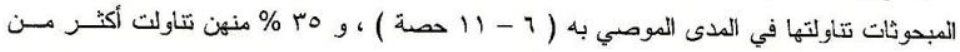

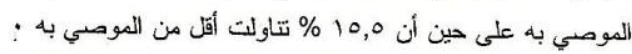

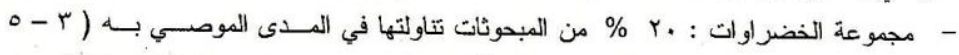

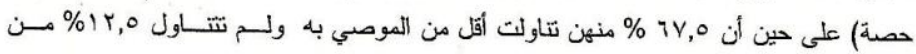

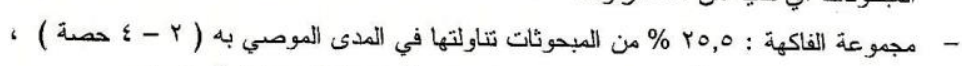

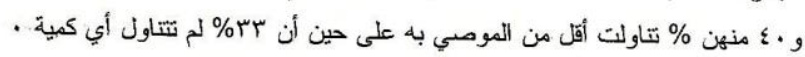

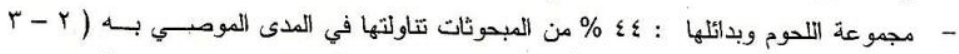

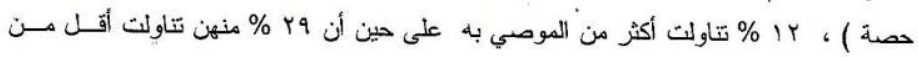

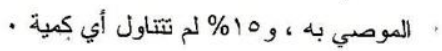

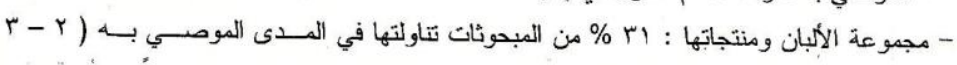

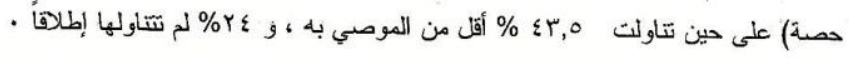


جذول ه. توزيع المبحوثات وفقاً لمدى نتاولهن الحصة اليومية الموصي بها من المجموعات الغذائية

\begin{tabular}{|c|c|c|c|c|c|c|}
\hline \multicolumn{2}{|c|}{ إجمالي العينة } & \multicolumn{2}{|c|}{ مبحوثات المعمورة } & \multicolumn{2}{|c|}{ مبحوثات خورشيد } & \multirow[t]{2}{*}{ المجموعات الغذائية } \\
\hline$\%$ & العدد & $\%$ & العدد & $\%$ & 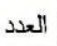 & \\
\hline & & & & & & مجموعة الخبز و الحبوب : \\
\hline$\leqslant 9,0$ & 99 & $0 ., \cdot$ & $\varepsilon \wedge$ & $\leqslant 9$, & 01 & في المدى الموصي به \\
\hline ro & $v$. & $r q, 7$ & ra & $r \cdot, \lambda$ & 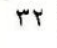 & أكثر من الموصي به \\
\hline 10,0 & r & $1 \cdot, \varepsilon$ & 1. & $r \cdot, r$ & ru & أقلّ من الموصي به \\
\hline & & & & & & مجموعة الخضر اوات : \\
\hline$r$. & $\varepsilon$. & 19,1 & 19 & $r \cdot, r$ & r) & في المدى الموصي به \\
\hline- & - & - & - & - & - & أكثر من الموصي به \\
\hline $4 V, 0$ & 1ro & $i \wedge, \wedge$ & 77 & $77, \varepsilon$ & 79 & أقلّ من الموصي به \\
\hline IY,O & Yo & 11,0 & 11 & 11 & $1 \leqslant$ & لم تتناول \\
\hline & & & & & & مجموعة الفاكهة : \\
\hline$r_{0,0}$ & 01 & 19,1 & 19 & $r \cdot, \Lambda$ & HT & في المدى الموصي به \\
\hline 1,0 & $r$ & - & - & $r, q$ & $r$ & أكثر من الموصي به \\
\hline$\varepsilon$ & $\wedge$. & $\varepsilon 1, V$ & 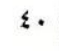 & $r \wedge, 0$ & $\varepsilon \cdot$ & أقل من الموصي به \\
\hline rי & 74 & rı,० & re & $r v, q$ & rq & لم تيتاول \\
\hline & & & & & & مجموعة اللدوم وبدائلها : \\
\hline$\leqslant \varepsilon$ & $\mathrm{A}$ & $\{7,9$ & $\leqslant 0$ & $\leqslant 1, \varepsilon$ & $\varepsilon r$ & في المدى الموصي به \\
\hline ir & $Y \varepsilon$ & $\Lambda, r$ & A & $10, \varepsilon$ & 17 & أكثر من الموصي به \\
\hline 19 & $0 \wedge$ & $r$ & Tr & ro,. & דיץ & أقل من الموصي به \\
\hline 10 & $r$. & 11,0 & 11 & $11, r$ & 19 & لم تيتاول \\
\hline & & & & & & مجموعة الألبان ومنتجاتها : \\
\hline ri,. & r & $17, \mathrm{~V}$ & 17 & $\varepsilon \varepsilon, r$ & $\varepsilon T$ & في المدى الموصي بـ \\
\hline 1,0 & $r$ & - & - & $r, q$ & r & أكثر من الموصي به \\
\hline$\varepsilon r, 0$ & $\wedge \mathrm{V}$ & $O \wedge, r$ & 07 & $r q, 9$ & r & أقل من الموصي به \\
\hline$r \varepsilon, \cdot$ & $\varepsilon \wedge$ & ro,. & $r \varepsilon$ & $r r, 1$ & $r \varepsilon$ & لم تثناول \\
\hline
\end{tabular}




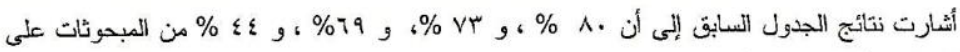

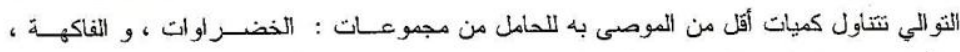

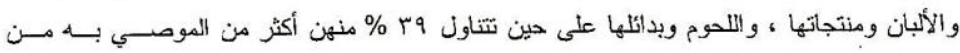

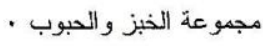

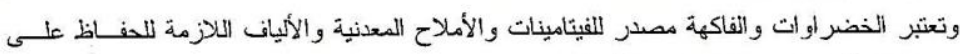

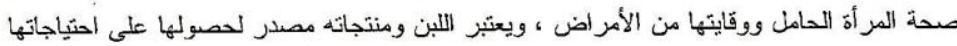

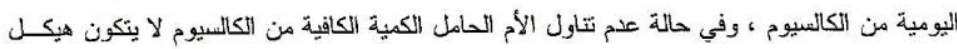

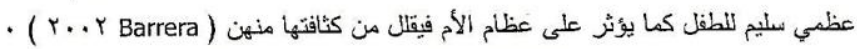
r - معدل المتناول أسبوعياً من مجموعة اللحوم ويدائلها :

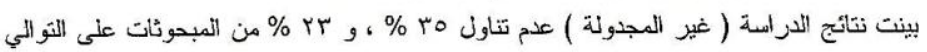

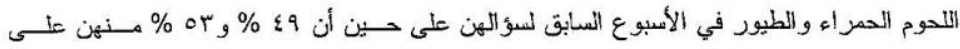

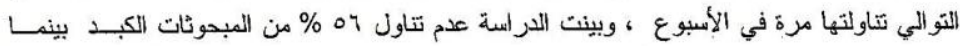

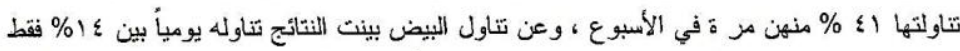

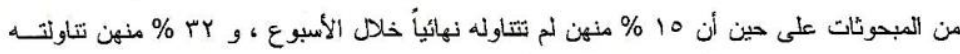

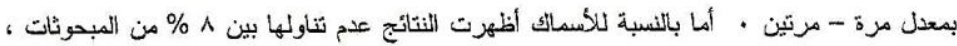

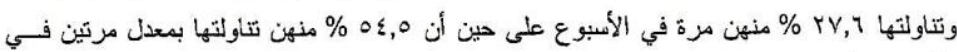
• الأسبوع فأكثر

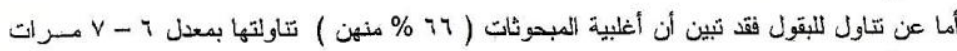

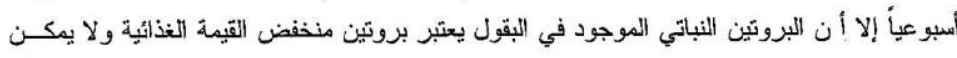

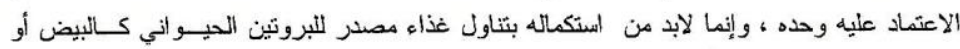

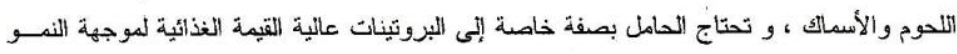

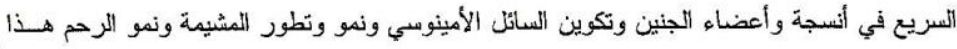

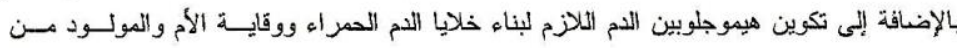

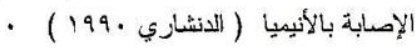

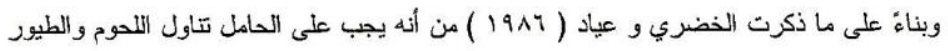

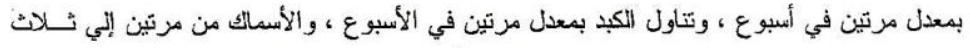

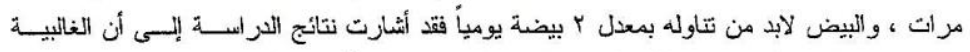

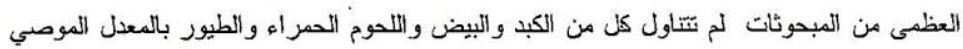

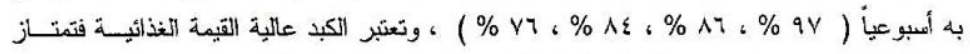

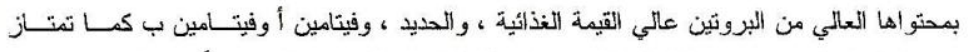

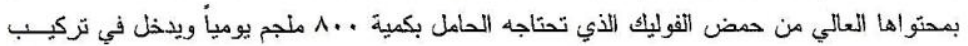

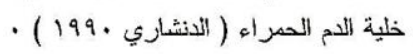


أما الأسماك فقد أنشارت نتائج الدراسة إلى أن أكثر من نصف المبحوثـات (

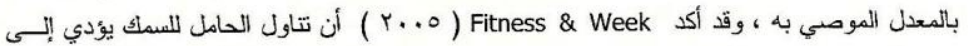

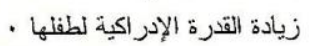

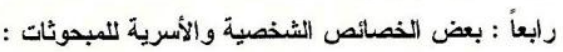

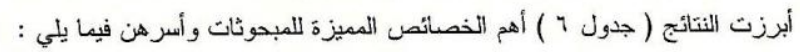

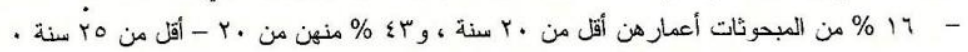

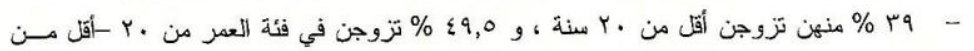
.

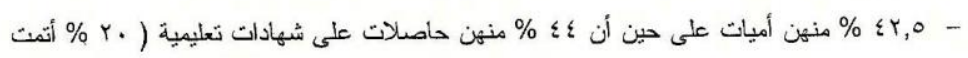

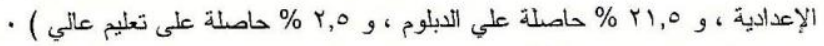

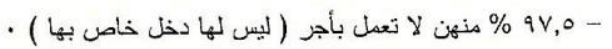

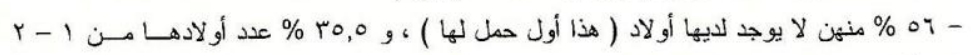

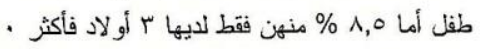
- 0 \% \% منهن بدأت منابعة الحمل مع الطبيب منذ بداية الحمل ( الشهر الأول أو الثناني ) على حين

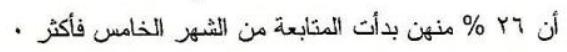
- 10 \% منهن مصدر معلوماتها في الشئون الخاصة برعاية وتغذية الحامل الأهل والأقارب والخبرة

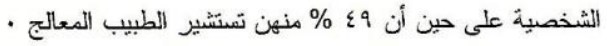

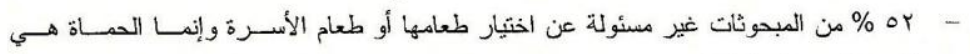

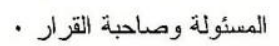

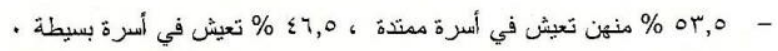

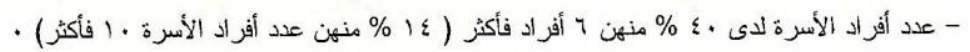

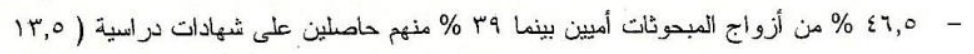

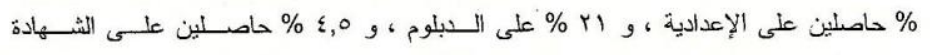

$$
\text { · الجامعية ) }
$$

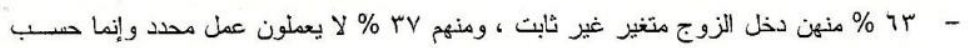

$$
\text { الظروف اليومية - منان }
$$


جدول 7 ـ توزيع المبحوثات وفقاً لبعض خصائصهن الشخصية والأسرية

\begin{tabular}{|c|c|c|c|c|c|}
\hline$\%$ & 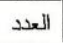 & الخصائص & $\%$ & 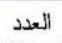 & الخصائص \\
\hline & & - عمرها عند الزواج : & & & - العمر الحالي للمبحوثة : \\
\hline rq & VA & أقل من · r سنة & 14 & re & أقل من · r سنة \\
\hline$\leqslant 9,0$ & 99 & من •r --" & $\varepsilon r$ & $\Lambda \tau$ & من •r ---- \\
\hline $1 ., 0$ & YI & من OY --- & rq & $0 A$ & من Yo --- \\
\hline \multirow[t]{2}{*}{$1, \cdot$} & r & هن ·r ---- & $\wedge$ & 17 & من ·r --" \\
\hline & - & أكثر من مr سنة & $\varepsilon$ & $\wedge$ & أكثر من مr سنة \\
\hline & & - تعليم الزوج : & & & - نعليمها : \\
\hline$\varepsilon \uparrow, 0$ & qז & لا يقرأ ولا يكتب & $\{r, 0$ & 10 & لا تقرأ ولا تكتب \\
\hline $1 \varepsilon, 0$ & rq & يقرا ويكتب & $1 \mathrm{r}, \mathrm{O}$ & rV & تقز ا وتكتب \\
\hline 15,0 & rv & أتم التعليم الأساسي & $r_{\bullet}, \cdot$ & $\varepsilon$. & أتمث التعليم الأساسني \\
\hline ५i, & $\varepsilon r$ & حاصل على الدبلوم & Y, 0 & $\leqslant r$ & حاصلة على الدبلوم \\
\hline$\varepsilon, 0$ & 9 & التعليمي العالي & r,o & 。 & الثعليم العالي \\
\hline \multirow{3}{*}{$\begin{array}{l}\varepsilon \uparrow, 0 \\
\text { or, }\end{array}$} & & - نوعية الأسرة : & & & - عملها بأجر : \\
\hline & 94 & بسيطة & $r, 0$ & $\circ$ & تعمل \\
\hline & $1 . v$ & غبر بسيطة & $9 \mathrm{~V}, 0$ & 190 & لا تعل \\
\hline \multirow{4}{*}{$\begin{array}{l}7 . \\
\text { ro } \\
10\end{array}$} & & - عدد أفزاد الأسرة : & & & - عدد أو لادها : \\
\hline & ir. & $0-Y$ & . ,, & $11 Y$ & لا يوجد \\
\hline & $\circ$. & $9-1$ & ro,o & (n) & r- 1 \\
\hline & r. & $1 \varepsilon-1$ & 1,0 & iv & r r فاكثر \\
\hline \multirow{3}{*}{$\begin{array}{l}r v \\
r r\end{array}$} & & - نوعية دخل الززوج : & & & مصادر معلوماتها عن رعاية وتغذية الحامل \\
\hline & $v \leqslant$ & ثابت & 01 & $1 . r$ & الخبرة والأهل و الأقارب \\
\hline & $1 Y 4$ & متغير & $\leqslant 9$ & 91 & الطبيب أو الطبيية \\
\hline \multirow{4}{*}{$\begin{array}{l}\varepsilon \wedge \\
\text { or }\end{array}$} & & مسنوليتها في اختيار الطعام & & & - متابعة الحمل مع الطبيب : \\
\hline & 97 & هي المسئولة & 07,. & $11 \mathrm{r}$ & من الشهر الأول أو الثاني - . \\
\hline & 1.5 & ليست هي المسئولة & $i v, 0$ & ro & من الشهر الثالث -- الز أبع \\
\hline & & & $r \uparrow, 0$ & or & من الشهر الخامس فأكثر \\
\hline
\end{tabular}

رابعاً : التطيل الإحصائي للنتائج البحثية لتحديد العلاقات بين متغيرات الدارسة :

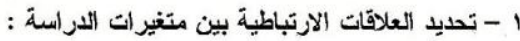

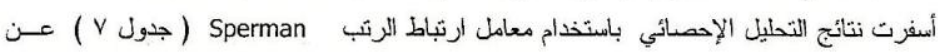

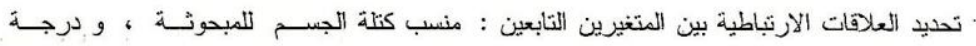

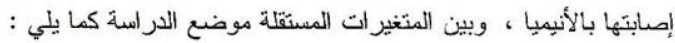

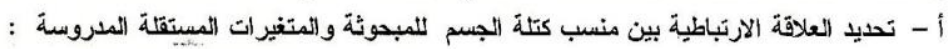

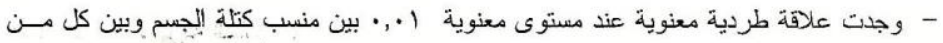

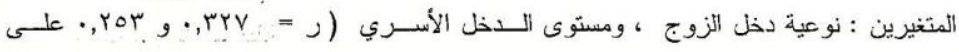




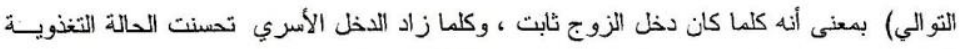

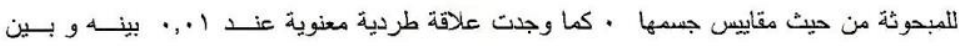

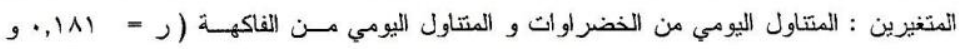

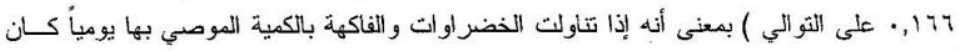

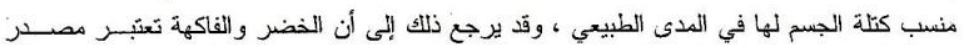

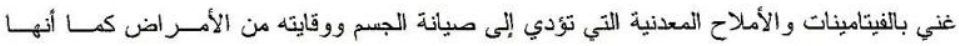

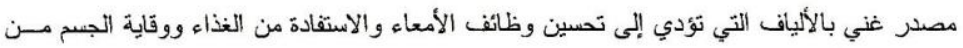

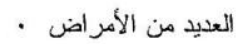

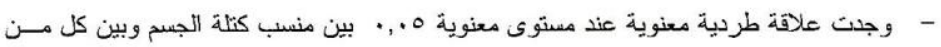

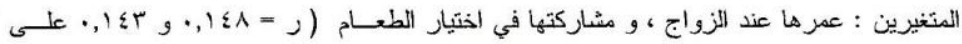

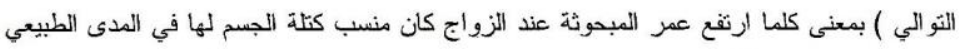

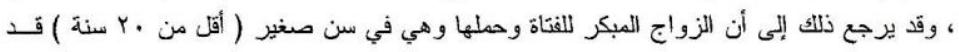

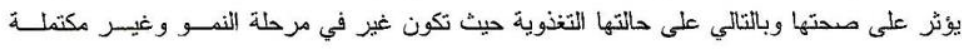

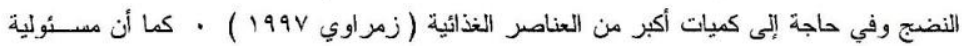

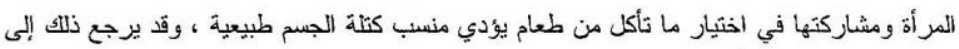

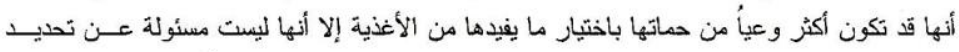

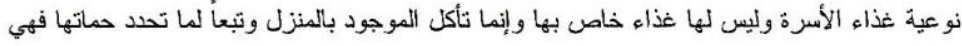

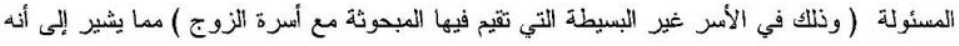

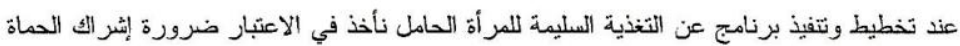

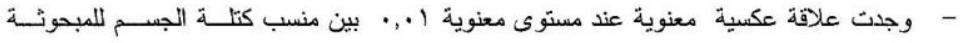

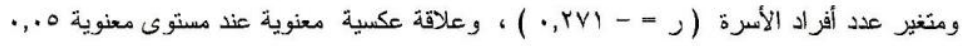

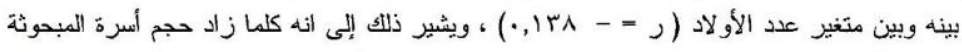

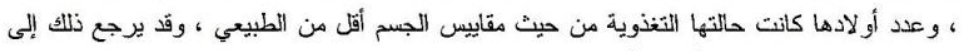

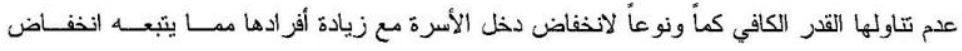

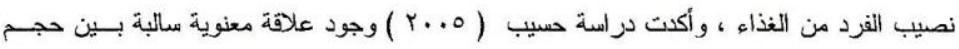

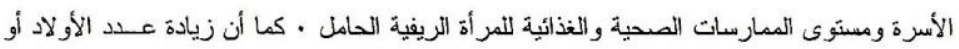

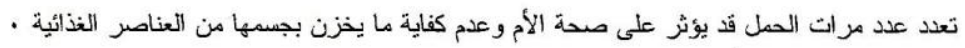

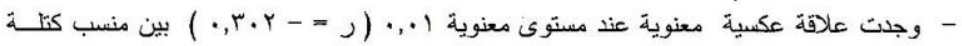

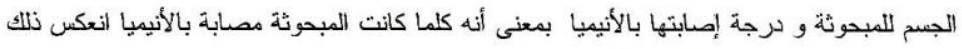

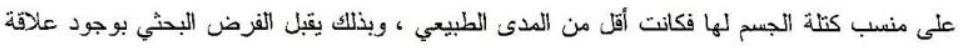

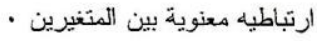

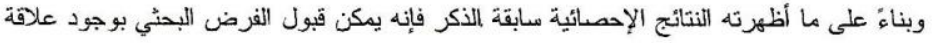

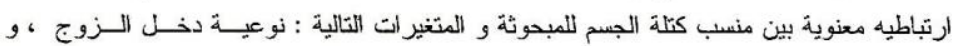


مستوى دخل الأسرة ، و عمر المبحوثة عند الزواج ، وعدد أولادها ، وعدد أفراد الأســرة ( فــي

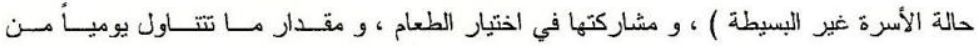

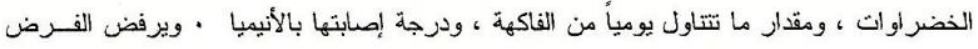

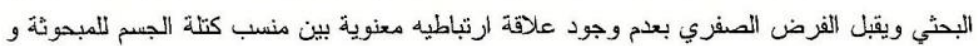

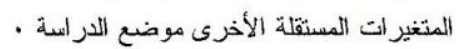

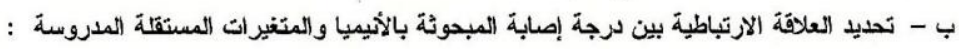

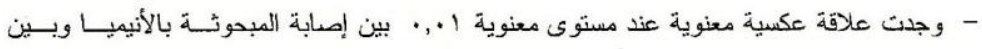

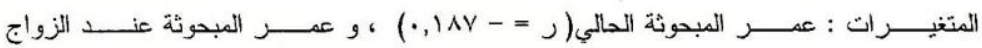

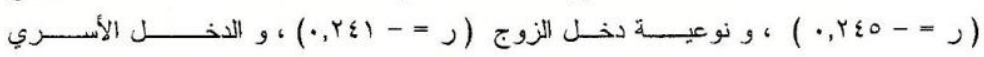

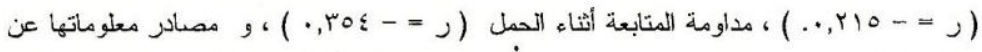

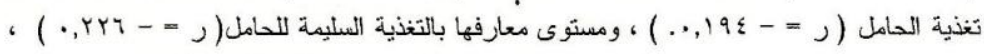

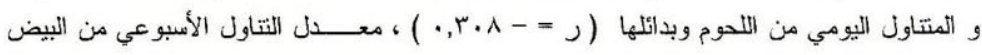
$\cdot(\cdot, \mathrm{r}) \mathrm{L}-=\jmath)$

- وجدت علاقة عكسية معنوية عند مستوى معنوية ه. . • بين إصـابة المبحوثـة بالأنيميـا وبـين

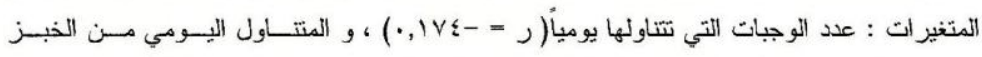

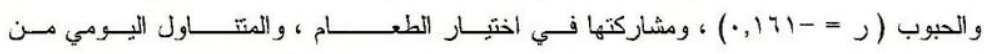

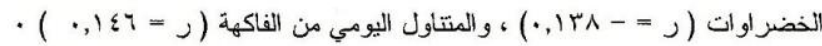

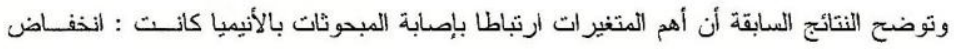
الدخل الأسري ، و عدم ثبات دخل الزوج ، و زواج المبحوثة في سن مبكر ، و و عدم مداومة متابعتها

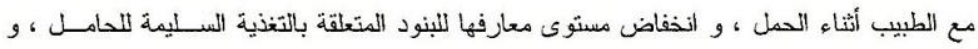

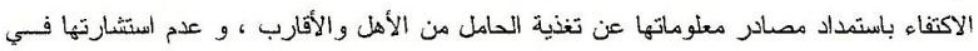

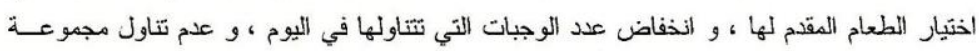

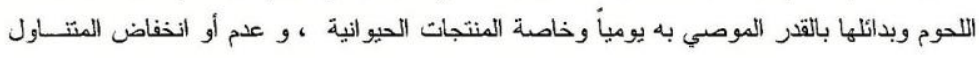

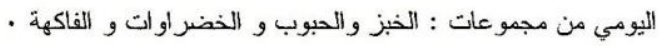
وبذلك يمكن قبول الفرض البحثي بخصوص المتغيرات المستقلة سابقة الذكر بوجود علاقة ارتباطيـهـ.

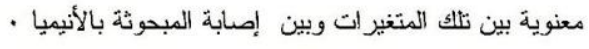




\begin{tabular}{|c|c|c|c|}
\hline درجة الإصابة بالأنيميا & منسب كتلة الجسم & \multirow{2}{*}{\multicolumn{2}{|c|}{ المتغير ات المستقلة }} \\
\hline قيم معامل الارتباط & قيم معامل الارنباط. & & \\
\hline$* * \cdot, \mid \wedge V-$ & $\cdot, \cdot \leq 0$ & العمر الحالمي للمبحوثة & - \\
\hline$* *, r \leqslant 0 \quad-$ & $* \cdot, 1 \leq \Lambda$ & عمرها عند الزواج & - \\
\hline$\cdot, \cdot Y q$ & $\cdot, 991$ & درجة تعليمها & - \\
\hline .,.or - & 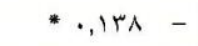 & عدد أو لادها & - \\
\hline$* *, r \circ 0 \leqslant-$ & $\cdot, \wedge \leq$ & مداومة المتابعة أثثاء الحمل & - \\
\hline$* *,, 19 \leq-$ & $\cdot, 11$ & مصلادر معلوماتها عن تغذية الحامل & - \\
\hline *.,IAr - & $* \cdot, 1 \leq r$ & مشاركتها في اختيار الطعام & - \\
\hline$*, 100$ & ${ }^{* *} \cdot$, YVI - & عدد أفراد الأسرة & - \\
\hline$\cdot,+70$ & $\cdot, .09$ & درجة تعليم الزوج & - \\
\hline$* *, Y \leq 1 \quad-$ & ** $\cdot$ * IYY & نوعية دخل الزووج & - \\
\hline **., r10 - & $* *$, ror & دخل الأسرة & - \\
\hline **, שY - & $\cdot, I Y Y$ & المستوى المعرفي للمبحوثة & - \\
\hline$\cdot \cdot, \mid \vee \varepsilon-$ & $\cdot, \cdot 79-$ & عدد الوجبات التي تثناونها يومياً & - \\
\hline$* ., 171-$ & $\cdot, .07$ & المتتاول اليومي من الخبز والحبوب & - \\
\hline * $\cdot$, & $* * \cdot,|\wedge|$ & المتتاول اليومي من الخضراوات & - \\
\hline$*, 1 \leq 7-$ & $* * \cdot, 17 \mathrm{~V}$ & المتتاون اليومي من الفاكهة & - \\
\hline$* * \cdot, r \cdot \Lambda-$ & ( & المتناول اليومي من اللحوم وبدائلها & - \\
\hline$\cdot, \cdot \varepsilon \varepsilon$ & $\cdot, \cdot \leq \xi r$ & المتتاول اليومي من الألبان ومنتجاتها & - \\
\hline$* * \cdot, \mu) \leqslant-$ & -- & معدن التتاون الأسبوعي من البيض & - \\
\hline $1, \cdots$ & **,r.r.r - & درجة إصابة المبحوثة بالأنيميا & - \\
\hline
\end{tabular}

r - تحديد العلاقة التأثيرية للمتغيرات المستقلة المدروسةً على كل من المتغيرين التابعين للاراسة :

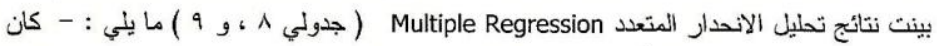

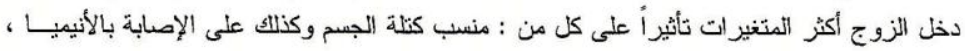

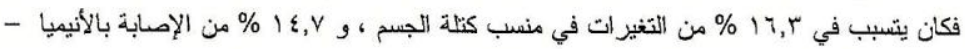

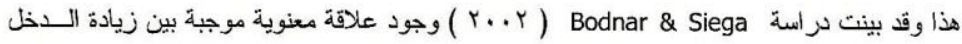

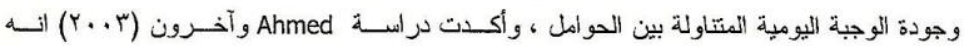

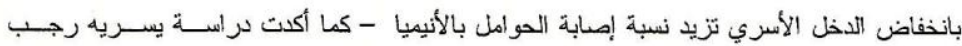

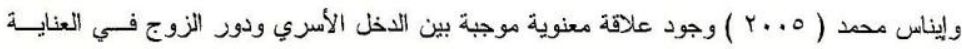

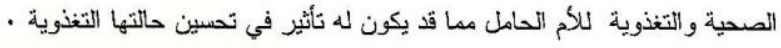




\begin{tabular}{|c|c|c|c|}
\hline مقدار تغير رץ & قيم رr & قيم در & المتغيرات المستقلة \\
\hline$\cdot,|r|$ & $\cdot|r|$ & $\cdot, r \leqslant V$ & 1 - مسئوليتها عن اختيار الطعام \\
\hline$\because, \ldots$ & $\cdot, 1$ Yo & , ror & r- عدد أفراد الأسرة \\
\hline ( & $\cdot$, YAA & . & ب- دخل الزوج \\
\hline$\cdot$, . or & $\cdot, r \leqslant$. & $\cdot, 0 \wedge \mu$ & ـ-دخل الأسرة \\
\hline , & $\cdot, \varepsilon \vee 1$ & $\cdot, 4 \wedge 7$ & ه-إصابتها بالأنيميا \\
\hline$\cdot, 94$ & 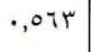 & $\cdot$, Vo. & ז-تئاولها اليومي من الخضر اوات \\
\hline$\cdot, \cdots 9$ & $\cdot, 0 \times 1$ & $\cdot, \mathrm{V} 07$ & V- تتاولها اليومي من الفاكهة \\
\hline
\end{tabular}

جدول 9 ـ المتغيرات المسنثلة المؤثرة على المتغير التابع إصابة المبحوثات بالأنيميا

\begin{tabular}{|c|c|c|c|}
\hline مقدار تغير ر r & قيم رץ & قيم ر & المتغيرات المسنقلة \\
\hline$\cdot, \cdots r$ & $\cdot, \cdots$ & $\cdot, .01$ & 1 - عمر المبحوثة عند الزواج \\
\hline$\cdot, \cdot \varepsilon Y$ & $\cdot, .0 \leqslant$ & $\cdot, Y \backslash 1$ & Y- مسئولينها عن اختيار الطعام \\
\hline$\cdot, \cdots\urcorner$ & $\cdot, .0$ & •, YY & r- عدد أفراد الأسزة \\
\hline$\cdot, 1 \leqslant V$ & $\cdot, 19 \mathrm{~V}$ & $\cdot, \varepsilon \varepsilon \varepsilon$ & ع- دخل الزووج \\
\hline$\cdot, \cdot r \mu$ & $\cdot, Y Y I$ & $\cdot, \varepsilon \vee$. & ๑- دخل الأسرة \\
\hline$\cdot, \cdots 1$ & - YYY & $\cdot, \sum \vee 1$ & צ- - مستوى معارفها عن تغذية الحامل \\
\hline$\cdot, \cdot \varepsilon r$ & $\cdot, Y 77$ & $\cdot, 010$ & V- درجة متابعة الحمل \\
\hline
\end{tabular}

توصيات البحث

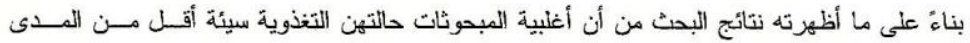

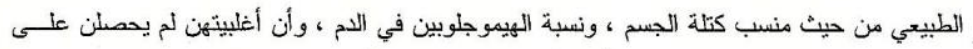

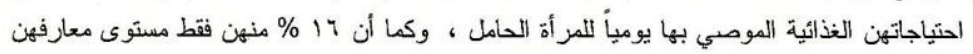

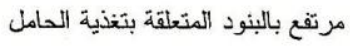

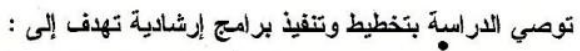

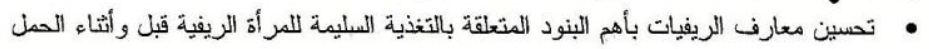

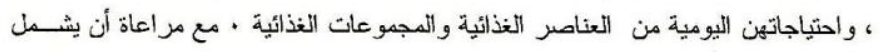

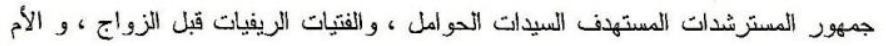

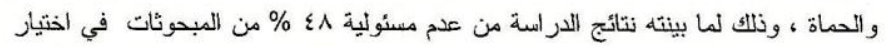

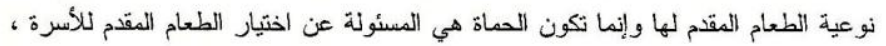

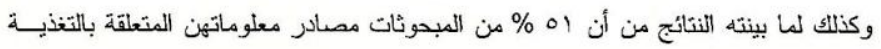

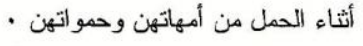


• إكساب الريفيات المهارات الخاصة بإعداد وجبات غذائية للمر أة الحامل تغطي احتياجاتهـا

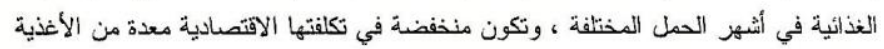

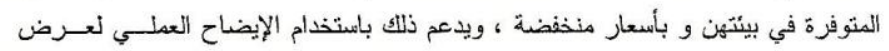

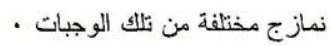

• تدريب الريفيات على بعض الصناعات الصغيرة من الخامات البيئية المنــوفرة وتشـــــيعها

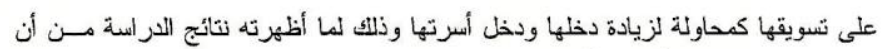

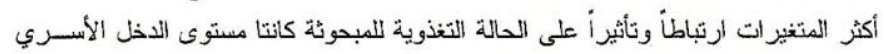

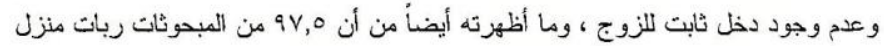

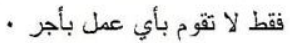

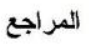

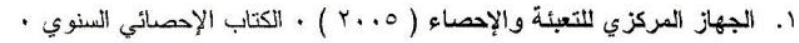

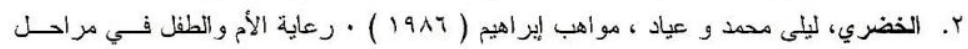

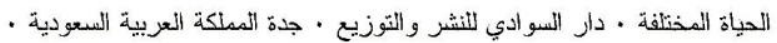

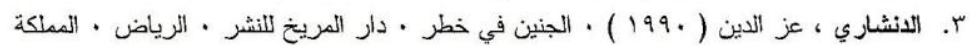

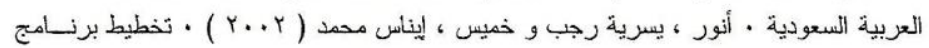

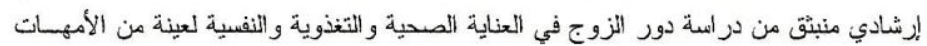

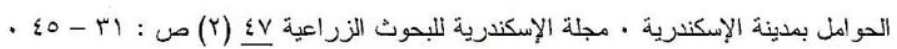

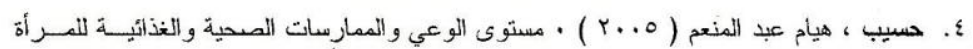

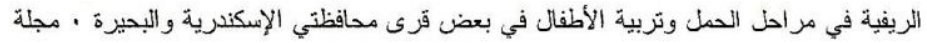

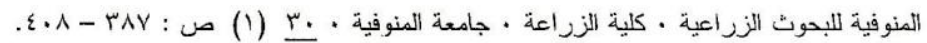

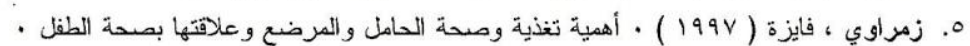

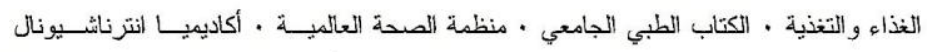

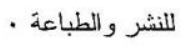

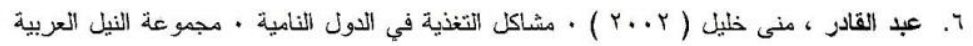

$$
\text { · مدينة نصر · القاهرة . }
$$

7. Ahmed, F. Mahmude, I. Abeda Sattar and M. Akhtaruzzaman. 2003. Anemia and vitamin A deficiency in poor pregnant women of Bangladesh. Asia Pacific Journal of Clinical Nutrition, 12 (4) : 460-466.

8. Barrera, S. M. 2002. Stronger bones - nutrition - important for pregnant women to consume calcium for baby's health - Brief Article .www.findarticles. com.

9. Bodnar , L . and A. M. Siega - Riz. 2002. A diet quality index for pregnancy detects variation in diet and differences by sociodemographic factors. Public Health Nutrition, $\underline{5}(6): 801-809$. 
10. Bondevik, G. T., M. Ulstein and G. Kvale. 2001. Maternal hematological status and risk of low birth weight and preterm delivery in Nepal. Acta Obstetricia et Gynecologica Scandinavica 80 (5) : $402-408$.

11. CSPRO 2005. Nutritional Status and Anemia Level. www.cspro.org/pubs/pdf/FR $176 /$

12. Deckelbaum. 2002. Nutrition During Pregnancy and Lactation. Clinical Practice Lecture . Morgan Grams 3 May .

13. Ghorashi , F .E. and T. Heidari. 2004. Iron status of babies born to iron deficient anemic mothers in an Iranian hospital . Eastern Mediterranean Health Journal 10 (6) $: 808-814$

14. Fitness, O. and W. Week. 2005. Diet and Nutrition, fish consumption by women may increase infants' cognitive ability. http : // proquest. umi.com. Atlanta : Oct $29 \mathrm{p}: 1484$.

15. Hand , B . and R. Dietician. 2005. Low Carbohydrates and Pregnancy. www. Babyfit.com.

16. Jiang, T., P. Christian, S. K. Khatry and P. Keith. 2005. Micronutrient Deficiencies in Early Pregnancy are Common, Concurrent, and Vary by Season among Rural Nepali Pregnant Women. The American Society for Nutritional Sciences . J . Nutr . 135: 1106-1112. May.

17. Rush, D. 2000. Nutrition and maternal mortality in the development world . American Journal of Clinical Nutrition, $\underline{72}$ (1) : $212-240$.

18. Jood, S. , S. Bishnoi and N. Khetarpaul. 2002. Nutritional status of rural pregnant women of Haryana State, Northern India. Nutrition and Health 16 (2) : 121-131.

19. SCC 1997. Nutrition for Pregnant Women. http://scc.uuchicago.edu/nutritiopregnant. htm. 


\title{
THE RELATIONSHIP BETWEEN NUTRITIONAL STATUS OF RURAL PREGNANT WOMEN AND SOME VARIABLES IN SOME VILLAGES AT ALEXANDRIA GOVERNORATE
}

\author{
AMAL EL SAYED EL ASAL
}

Agricultural Extension AND Rural Development Research Institute, ARC, Giza, Egypt

(Manuscript received 23 May 2006)

Abstract
This study aimed to : 1 - Assess and evaluate the nutritional status
of respondents (their body mass index, and their blood
hemoglobin concentration ). 2 - Determine awareness about
nutrition. 3 - Assess the daily dietary pattern of the respondents.
4 - Determine the relationships between the nutritional status of
respondents and some independent variables i.e. socioeconomic,
daily dietary pattern, women 's nutritional knowledge level.
Data were collected by personal interview using a questionnaire
sheet. The sample included 200 pregnant rural women from Health
Unite Visitors in Khorshed and El Mahmora in Alexandria
governorate.

The results of the present study indicated that:

- $58 \%$ of respondents women were considered underweight.

- $\quad 44 \%$ of respondents women were classified as anemic.

- $23 \%$ of respondents the nutritional awareness level was low while $61 \%$ of them had the moderate level.

- $80 \%, 73 \%, 69 \%$ and $44 \%$ of respondents in the respective order were lower than the daily recommended from food groups consumed by vegetables, fruit, milk and meat .

- There were significant positive relationships between women's body mass index (as dependent variable) and some independent variables i .e. : family income, kind of husband income, marriage age, vegetables and fruit intakes. However There were significant negative relationships with numbers of children and family size.

- There were significant positive relationships between women's body mass index (as dependent variable) and anemic infection ( as independent variable)

- There were negative significant relationships between anemic infection ( as a dependent variable ) and women's age, here marriage age, follow up with doctor during pregnancy, information sources, kind of their husband income, level of family income, level of their nutritional awareness, their daily consumption meats and its intakes of alternatives, family size , participating in food choosing , numbers of meals and serving daily from each of vegetables and fruit . 